\title{
Patterns of non-medical use of methylphenidate among 5th and 6th year students in a medical school in southern Brazil
}

\author{
Padrões do uso não médico de metilfenidato em estudantes do $5^{\circ}$ e do $6^{\circ}$ ano \\ de uma faculdade de medicina do Brasil
}

\author{
Rodrigo da Rosa Silveira, ${ }^{1}$ Betina Lejderman, ${ }^{2}$ Pedro Eugênio Mazzucchi Santana Ferreira, ${ }^{3}$ \\ Gibsi Maria Possapp da Rocha ${ }^{4}$
}

\begin{abstract}
Objectives: To evaluate the prevalence of methylphenidate (MPH) use among 5th and 6th year medical students, to discriminate MPH use with and without medical indication, and to correlate MPH use with alcohol intake.

Methods: This is a cross-sectional study in which medical students were invited to answer a questionnaire to evaluate academic and socioeconomic status, MPH use patterns, and attitudes towards neuroenhancing drugs. The Alcohol Use Disorders Identification Test (AUDIT) was used to assess alcohol intake; a score $\geq 8$ suggests potentially hazardous alcohol use.

Results: Fifty-two participants (34.2\%) had already used MPH, of which $35(23.02 \%)$ had used it without medical indication. The number of 6 th year students who had used $\mathrm{MPH}$ was more than twice higher than that of their 5 th year counterparts (32.89 vs. $13.15 \%$, respectively; $p=0.004)$. Also, $43.6 \%(p=0.031)$ of the users of MPH had an AUDIT score $\geq 8 ; 33.3 \%(p=0.029)$ of non-medical users of MPH had an AUDIT score $\geq 8$.

Conclusions: In this study, the use of $\mathrm{MPH}$ without medical indication was prevalent. Our findings also confirmed the association between non-medical use of MPH and potentially hazardous alcohol use.
\end{abstract}

Keywords: Methylphenidate, attention deficit disorder with hyperactivity, ethics, alcohol abuse.

\begin{abstract}
Resumo
Objetivos: Avaliar a prevalência do uso do metilfenidato entre estudantes do $5^{\circ}$ e do $6^{\circ}$ ano de uma faculdade de medicina, discriminar o uso com ou sem indicação médica e correlacionar o uso de metilfenidato com a ingestão de álcool.

Métodos: Este é um estudo transversal, em que os alunos de medicina foram convidados a responder um questionário para avaliação do status socioeconômico e acadêmico, padrões do uso do metilfenidato e atitude em relação a drogas potencializadoras da cognição. Também foi aplicado o questionário The Alcohol Use Disorder Identification Test (AUDIT), que avalia o consumo de bebidas alcoólicas, onde um score $\geq 8$ significa ingestão potencialmente perigosa de álcool.
\end{abstract}

Resultados: Cinquenta e dois participantes (34,2\%) já haviam usado metilfenidato, sendo que 35 destes $(23,02 \%)$ haviam usado a substância sem indicação médica. $O$ número de estudantes do $6^{\circ}$ ano que fizeram uso não médico de metilfenidato foi mais de duas vezes maior do que o número de estudantes do $5^{\circ}$ ano $(32,89$ versus $13,15 \%$, respectivamente; $p=0,004)$. Em relação ao AUDIT, 43,6\% ( $p=0,031)$ dos usuários de metilfenidato tiveram escores $\geq 8 ; 33,3 \%(p=0,029)$ dos usuários não médicos de metilfenidato tiveram escores $\geq 8$ no AUDIT.

Conclusões: Neste estudo, o uso de metilfenidato sem indicação médica foi prevalente. Os achados também evidenciaram a associação entre o uso não médico de metilfenidato e o uso potencialmente perigoso de álcool.

Descritores: Metilfenidato, transtorno do déficit de atenção com hiperatividade, ética.

\footnotetext{
${ }^{1}$ Psychiatrist, Pontifícia Universidade Católica do Rio Grande do Sul (PUCRS), Porto Alegre, RS, Brazil. 2 Physician, PUCRS, Porto Alegre, RS, Brazil. ${ }^{3}$ Department of Psychiatry, PUCRS, Porto Alegre, RS, Brazil. ${ }^{4}$ Assistant Professor of Psychiatry, Department of Psychiatry, PUCRS, Porto Alegre, RS, Brazil.

The present study was carried out at the Department of Psychiatry of Pontifícia Universidade Católica do Rio Grande do Sul (PUCRS), Porto Alegre, RS, Brazil. The paper was presented as a poster at the conference XI Jornada de Psiquiatria da APRS, held in September 5th to 7th, 2013, in Gramado, southern Brazil. Financial support: none.

Submitted Dec 16 2013, accepted for publication Feb 23 2014. No conflicts of interest declared concerning the publication of this article.

Suggested citation: Silveira RR, Lejderman B, Ferreira PE, da Rocha GM. Patterns of non-medical use of methylphenidate among 5th and 6th year students in a medical school in southern Brazil. Trends Psychiatry Psychother. 2014;36(2):101-106. http://dx.doi.org/10.1590/2237-6089-2013-0065
} 


\section{Introduction}

Methylphenidate (MPH), a substance that has been widely disseminated under its commercial name Ritalin ${ }^{\circledR}, 1,2$ is currently one of the world's top-selling central nervous system stimulants. ${ }^{1}$ In the last two decades, there has been an enormous increase in its production and consumption. ${ }^{1-3}$ This growth is explained by an increase in the diagnosis and treatment of attention deficit and hyperactivity disorder (ADHD) and also by the non-medical use (NMU) of MPH. ${ }^{1,4,5}$

According to the U.S. National Survey on Drug Use and Health, the NMU of substances is defined as "the use of prescription-type psychotherapeutic drugs not prescribed for the respondent by a physician or used only for the experience or the feeling they caused." ${ }^{1}$ For convenience, the term NMU will be used in this work only to refer to individuals that use MPH without a medical prescription for the treatment of a given neuropsychiatric disorder.

The use of MPH for the treatment of ADHD is sustained in several studies that have demonstrated its effectiveness and efficiency. ${ }^{1-4}$ Under the recommended dosage, it is considered a safe medication with a satisfactory level of side effects. When properly indicated, the chances of the drug leading to addiction are very low, and its use has actually been considered as a shield against the development of addiction in individuals with ADHD. ${ }^{1}$ Therefore, for the treatment of ADHD, MPH represents the gold standard treatment; that use of $\mathrm{MPH}$ is not within the scope of this paper.

From a different standpoint, there has been recent concern as to the NMU of MPH. Such use appears to be becoming popular mainly among college students. ${ }^{4,6}$ Several studies show that MPH has been used nonmedically especially for hedonistic purposes (e.g., to "get high") ${ }^{7-9}$ and in the expectation of cognitive enhancement by healthy individuals. 5,10 The NMU of $\mathrm{MPH}$ seems to have grown in proportion to the number of prescriptions for the treatment of disorders such as ADHD; in some groups, the NMU of MPH seems to be actually greater than the use with therapeutic purposes. ${ }^{9,11}$ Therefore, there is a call for further study and discussion of the topic.

The use of $\mathrm{MPH}$ for cognitive enhancement came to prominence in the scientific field and popular media mainly after a 2008 article published online in the journal Nature, entitled "Poll results: look who's doping." The paper showed results of a poll carried out amongst readers of the journal all over the world. One in every five of the 1,400 participants admitted to use stimulants to improve work performance. ${ }^{12}$ Among those who used such substances, MPH was the drug of choice, accounting for $62 \%$ of the total. Evidence has suggested that MPH improves executive functions and memory in healthy individuals ${ }^{13}$; some authors advocate its use, legalization and even the encouragement of such use. ${ }^{12,14,15}$ However, the use of $\mathrm{MPH}$ for cognitive enhancement is controversial, because neither drug efficacy nor the benefit-risk balance provide sufficient evidence for this use. ${ }^{16,17}$

Moreover, MPH has some abuse potential, especially when used at an inappropriate dosage..$^{8,18}$ In this regard, the use of $\mathrm{MPH}$ for hedonistic purposes is regularly done via inhalation and simultaneously with other substances. ${ }^{1,19}$ Also, the route of administration, drugs used in combination with $\mathrm{MPH}$, and $\mathrm{MPH}$ dosage alter the safety profile of the medication. Thus, MPH use is associated with dangers such as addiction and severe side effects such as convulsions and hallucinations. 1,6,20

The addictive potential of $\mathrm{MPH}$ may be due to some effects of $\mathrm{MPH}$ in the brain that are similar to those of cocaine. ${ }^{20} \mathrm{MPH}$ inhibits the dopamine carrier, which increases synaptic levels of the neurotransmitter dopamine; this process is presumed to mediate the reinforcing effects and abuse potential of $\mathrm{MPH}$. The difference between the two substances lies essentially on the fact that MPH has a different pharmacokinetics: $\mathrm{MPH}$ clears from the brain at a significantly slower rate than cocaine, which seems to explain the relatively low potential of MPH abuse when used medically. 1,20-22 However, when inhaled, the speed at which the drug is delivered to the brain changes, and the risks of abuse are possibly greater.

Several studies suggest that the NMU of $\mathrm{MPH}$ is associated with higher rates of the use of other substances among students, such as heavy episodic drinking. ${ }^{9}$ Non-medical users of prescription stimulants were over six times more likely to report high-risk alcohol behavior. ${ }^{11}$ Particularly, MPH seems to be used simultaneously with alcohol to produce euphoric effects and reduce the negative sensations of drunkenness. ${ }^{23}$ It is known that using more than one drug at the same time can produce a synergistic effect beyond the additive effect of each drug. ${ }^{1,11}$ The simultaneous use of MPH and alcohol results in the production of a metabolite called ethylphenidate, of unknown toxicity. ${ }^{23}$ Because the use of both MPH and alcohol is high, and co-administration of both substances is known to be prevalent, this topic deserves further investigation.

The NMU of MPH has originated several studies, mostly carried out in the U.S., the world's biggest producer and consumer of the substance. Those studies have demonstrated that this use is prevalent especially among college students, $, 1,2,4,6,19$ with rates varying from 1.5 to $31 \%$ - lower in studies with samples representative of the national population and greater in 
studies investigating smaller, more specific populations. ${ }^{1}$ A 2009 review concluded that economically and socially privileged college students, as well as users of multiple substances, were at greater risk of making NMU of MPH. ${ }^{1}$ Moreover, studying in more competitive environments, where admission is more difficult, has been pointed out as a risk factor in some studies. ${ }^{24}$ Among the main motivations for the NMU of MPH it is possible to mention increased concentration, use as an aid to studying, and use to "get high." Thus, it is already well-documented that the non-therapeutic use of MPH is prevalent among college students, in several countries already studied.

In Brazil, as also in the U.S., there has been a major increase in the consumption of $\mathrm{MPH}$. National data, published in a review on $\mathrm{MPH}$, have described an increase in consumption, from only 2001 to 2006, of more than $468 \% .{ }^{25}$ In spite of this increase in $\mathrm{MPH}$ consumption in Brazil, there are no data available, to the best of the authors' knowledge, concerning the prevalence of NMU of MPH.

Therefore, the objectives of the present study were: to evaluate the prevalence of the use of $\mathrm{MPH}$ among medical students attending a university located in southern Brazil; to distinguish between the use of MPH with medical prescription for the treatment of neuropsychiatric disorders vs. its NMU; to assess, among non-medical users, when they began using MPH and their frequency and motivations for doing so; to assess the students' attitudes towards the use of neuroenhancing drugs; and, finally, to correlate the use of MPH with abusive alcohol consumption.

\section{Method}

\section{Ethics}

The protocol of this study was approved by the Ethics Committee of Hospital São Lucas of Pontifícia Universidade Católica do Rio Grande do Sul (PUCRS), Brazil, and all the participants signed an informed consent form before entering the study. This form was developed to fulfill the requirements of Brazil's National Health Council (Resolution no. 196/1996) and the Code of Ethics of the World Medical Association (Declaration of Helsinki). Participation was anonymous and voluntary, and participants could leave the study at any time without justification.

\section{Study design}

The dataset of the current study derived from a multiple-session cross-sectional survey carried out over a 1-month period at a medical undergraduate course of a university in southern Brazil.
Table 1 - Descriptive statistics based on MPH use and correlation with academic year

\begin{tabular}{lcccc}
\hline Year & \multicolumn{2}{c}{ All MPH users } & \multicolumn{2}{c}{ NMU of MPH } \\
\cline { 2 - 5 } & $\mathbf{n}(\%)$ & $\mathbf{p}$ & $\mathbf{n}(\%)$ & $\mathbf{p}$ \\
\hline 6th $(\mathrm{n}=76)$ & $35(46.05)$ & 0.006 & $25(32.89)$ & 0.004 \\
5 th $(\mathrm{n}=76)$ & $17(22.76)$ & & $10(13.15)$ & \\
\hline
\end{tabular}

$\mathrm{MPH}=$ methylphenidate; $\mathrm{NMU}=$ non-medical use.

\section{Sample and sampling procedure}

All medical students enrolled in the 5 th and 6 th year were contacted and invited to take part in the study. Target participants were approached directly at university facilities (i.e., outpatient clinics, classrooms) by the research staff; they were than invited to participate and informed of research goals and data collection procedures. Of the 156 students enrolled, 152 were contacted, and all agreed to participate in the study.

Participants were asked to complete self-report questionnaires and to subsequently deposit them in a locked box. In order to encourage respondent reliability and anonymity, participants were assured that the box would remain closed until completion of the data collection phase.

\section{Instruments}

Based on literature findings, $, 6,7,12$ a questionnaire was developed, comprising 25 items, organized into three sections: the first section, comprising eight items, was designed to evaluate academic and socioeconomic status; the second was designed to assess MPH use patterns, including first time of use, frequency of use, motivation to use, use with and/or without prescription, and use of drugs of abuse; the last section comprised five items, designed to gauge the respondent's attitudes towards neuroenhancing drugs. All variables were measured using binary or multiple-choice scales.

The Alcohol Use Disorder Identification Test (AUDIT) is a 10 -item self-report screening scale developed by the World Health Organization to evaluate patterns of alcohol use, including consumption, drinking behavior, and alcoholrelated problems. The test is a simple instrument, widely used to identify risky or harmful alcohol consumption as well as alcohol dependence and abuse. Scores range from 0 to 40, and a AUDIT score $\geq 8$ identifies potentially hazardous alcohol intake. ${ }^{26-28}$ AUDIT has been validated in Brazil, and many studies have confirmed the efficiency of the instrument, both in the general population and also among university students. ${ }^{29-31}$

\section{Data analysis}

Categorical data were expressed using frequency and percentage, and quantitative data, mean and standard deviation. The chi-square test was used to 
assess associations between demographic and academic variables, MPH use, and AUDIT scores.

Table 2 - Descriptive statistics on non-medical use of MPH

\begin{tabular}{l} 
Variable \\
\hline Distribution between genders \\
Women \\
Did not respond \\
Use onset \\
Elementary school \\
High-school \\
College preparatory school \\
College \\
Use frequency \\
Daily \\
Weekly \\
Monthly \\
Once a year \\
Use motivation (cumulative answers) \\
To study \\
To stay awake \\
To improve concentration \\
Experimentation \\
To get high \\
To lose weight \\
To go to parties \\
To clean the house \\
None of the above \\
Other reasons
\end{tabular}

Association with other substances

Never used MPH along with other substances

Alcohol

Marijuana

Cocaine

Others

MPH access

Medical prescription

$9(25.71)$

Friends, relatives (no cost)

Via the internet without prescription

Other

$25(71.42)$

0

$1(2.85)$

Inhaled use

No

Yes

$35(100.00)$

0

Use of illicit drugs in the past month

\begin{tabular}{cc} 
No & $32(91.42)$ \\
Yes & $3(8.57)$ \\
\hline
\end{tabular}

$\mathrm{MPH}=$ methylphenidate

104 - Trends Psychiatry Psychother. 2014;36(2)

\section{Results}

\section{Academic and socioeconomic status}

The final sample comprised 152 volunteers equally divided between the 5th and 6th year. Of the total, 55 $(36.2 \%)$ were male, 91 (59.9\%) were female, and 6 (3.9\%) did not respond. Mean age was $25.18 \pm 2.76$ years. Most participants lived with their parents $(89 ; 58.6 \%)$ and declared that their mean grade at university was between 8.5 and 10. Family income was between $R \$ 10,000.00$ and $\mathrm{R} \$ 20,000.00$ for $33.8 \%$ of the participants, and higher than $\mathrm{R} \$ 20,000.00$ for $33.1 \%$. In relation to feeling pressured by academic obligations, $46.7 \%$ of the participants said they felt just a little pressured. Among these variables, an association with MPH use was found only with the year that participants were attending. Table 1 details MPH use according to the year that participants were attending.

In the studied sample, 52 participants (34.2\%) had already used $\mathrm{MPH}$, of which $35(23.02 \%)$ had used it without medical indication or for non-medical reasons.

Between the 35 non-medical users of $\mathrm{MPH}, 29$ $(82.85 \%)$ began using it in college, and $16(45.7 \%)$ used it daily or weekly; 25 (71.4\%) got it for free from friends. The motivations to use MPH among these users were: 24 $(68.57 \%)$ to help in the studies; $11(31.42 \%)$ to improve concentration; $11(31.42 \%)$ for experimentation; 6 $(17.14 \%)$ to stay awake; and $2(5.71 \%)$ to go to parties. $\mathrm{NMU}$ of $\mathrm{MPH}$ found no association with gender ( $\mathrm{p}=$ $0.366)$, which was well distributed, with 14 (25.45\%) men and 18 (19.78\%) women. Table 2 details MPH use patterns among non-medical users.

\section{Associations between MPH use and alcohol intake}

Among non-medical users of $\mathrm{MPH}, 6$ (17.14\%) reported to have used $\mathrm{MPH}$ simultaneously with other drugs; among these, $5(14.2 \%)$ reported having used it simultaneously with alcohol. The results showed that both overall use of MPH (i.e., regardless of prescription) and NMU of MPH were associated with AUDIT scores $\geq 8$, which means potentially hazardous alcohol intake. Table 3 details MPH use and AUDIT scores.

\section{Attitudes towards the use of MPH}

Regarding attitudes towards the use of a medication with mild side effects as a cognitive enhancer, 135 (88.8\%) participants agreed on its use in people with memory and concentration problems resulting from neuropsychiatric disorders; 68 (44.7\%) agreed on its use in healthy individuals; $102(67.1 \%)$ said that they would use it themselves; and $31(20.4 \%)$ would prescribe it to boost cognitive functions in healthy individuals. 
Table 3 - Descriptive statistics based on MPH use and correlation with AUDIT scores

\begin{tabular}{lcccc}
\hline \multirow{2}{*}{ AUDIT (n) } & \multicolumn{2}{c}{ All MPH users } & \multicolumn{2}{c}{ NMU of MPH } \\
\cline { 2 - 5 } & $\mathbf{n}(\%)$ & $\mathbf{p}$ & $\mathbf{n}(\%)$ & $\mathbf{p}$ \\
\hline Score $\geq 8(n=54)$ & $25(46.3)$ & 0.031 & $18(33.3)$ & 0.029 \\
Score $<8(n=98)$ & $27(27.6)$ & & $17(17.3)$ & \\
\hline
\end{tabular}

$\mathrm{MPH}=$ methylphenidate; $\mathrm{NMU}=$ non-medical use; AUDIT $=$ Alcohol Use Disorder Identification Test.

Among the study participants, $26(17.1 \%)$ said that they would feel pressured if they knew that colleagues were taking cognitive enhancers to prepare for qualifying tests.

\section{Discussion}

The present study concluded that $23.02 \%$ of our sample of 152 participants had made NMU of MPH. This finding is in accordance with previous research: in a sample of 283 students attending an art school, a prevalence of $16 \%$ was found, ${ }^{32}$ while in another study involving 150 psychology students, the prevalence was $31.3 \% .^{33} \mathrm{~A}$ review carried out on the subject among college students found that rates ranged from 1.5 to $31 \%$, with higher prevalence rates being reported by studies with convenience samples, in which populations with a higher risk of NMU of $\mathrm{MPH}$ were studied. ${ }^{1}$ According to that review, a major risk factor for NMU of MPH is studying in a highly competitive environment, with people with greater purchasing power.

The vast majority of non-medical users of $\mathrm{MPH}$ in our sample $(85.71 \%)$ began use in college. These results are also in accordance with what is described in the literature. For example, in a study involving 3,500 students of a public university in the U.S., $79 \%$ of those who had made $\mathrm{NMU}$ of MPH had begun using it during college. ${ }^{7}$ Added to this is the fact that, when comparing people of the same age who are vs. those who are not in college, the NMU of prescription stimulants among college students is more prevalent. ${ }^{1}$ These findings support the idea that being a college student is a risk factor for NMU of MPH.

Another finding of this study that confirms previous data is that a majority of $71.4 \%$ acquired the medication free from friends. A study involving 9,161 students of a university in the U.S. found that $68 \%$ had obtained the medication for free from their colleagues. ${ }^{34}$ This corroborates the idea that having a classmate using $\mathrm{MPH}$ with medical prescription increases the risk of NMU of the substance, and also that NMU of MPH increases in proportion to the indication of the drug for the treatment of disorders. Moreover, the results demonstrated that NMU of $\mathrm{MPH}$ is more prevalent than its use with therapeutic purposes, as some authors had already suggested. ${ }^{9}$
The motivations for NMU of $\mathrm{MPH}$ were also similar to those previously described in literature. The main motivations found in this work for NMU of MPH were to help in the studies, mentioned by $68 \%$, and increased concentration, referred by $31.42 \%$. The use of $\mathrm{MPH}$ with hedonistic purposes (e.g., taking the medication to go to parties) was informed by $5.71 \%$ of the population, and its use simultaneously with alcohol was reported by $14.28 \%$. All these findings were similar to previous reports; for instance, in the study with psychology students, the simultaneous use of MPH and alcohol was reported by $19.3 \%$ of the sample. ${ }^{33}$

In addition to the simultaneous use of $\mathrm{MPH}$ and alcohol, the study found a significant correlation ( $p=$ 0.029 ) between NMU of $\mathrm{MPH}$ and alcohol consumption at levels representing risk to health. This finding is in accordance with previous studies that concluded that non-medical users of MPH were significantly more likely to engage in alcohol abuse and report adverse alcohol consequences. ${ }^{11}$ Conversely, another reason for concern about NMU of MPH described in the literature, namely, the inhaled use of $\mathrm{MPH}$, suggested as prevalent in a review on the topic, ${ }^{1}$ was not found in our sample.

Another significant correlation found in the present study was between NMU of MPH and the year that participants were attending. The number of 6th year students who had used MPH was more than twice higher than that of their 5 th year counterparts $(p=0.004)$. Among the 6 th year participants, $46.05 \%$ used MPH. This increased use in the last year of university is mostly non-medical and could be due to the approaching selection exams for medical residencies. Thereby the increased use of $\mathrm{MPH}$ would be motivated by a search for enhanced performance.

Concerning attitudes towards the use of a medication for cognitive enhancement, the study results were as follows: $88.8 \%$ agreed on the use of MPH by individuals with correlated neuropsychiatric disorder; $44.7 \%$ agreed on its use by healthy individuals; and $67.1 \%$ said that they would use it themselves. These findings are quite similar to those of an informal survey including 1,400 readers of the journal Nature. The percentage found in that survey for these three questions was, respectively, 96,45 , and $69 \% .{ }^{12}$ Additionally, $20.4 \%$ of the participants of the present study reported that, if they were doctors, they would prescribe controlled medication with small side effects to healthy individuals to help improve their cognitive performance.

The present findings should be analyzed in the context of some methodological limitations. Given the nature of the study, the small sample size is an important issue. Therefore, interpretation of the findings should consider psychosocial, economic, and biological plausibility aspects, and definite conclusions should only be drawn after independent replications. 


\section{Conclusions}

The NMU of MPH is probably as prevalent among Brazilian university students as in the other countries where this practice had already been studied. Similarly, NMU of this substance is also associated with alcohol abuse in Brazil. The simultaneous use of alcohol and MPH is a problem that needs to be better investigated, as very little is known about the deleterious health effects of this pattern of use, which is not rare. In this scenario, clinicians need to be careful in controlling the amount of $\mathrm{MPH}$ prescribed and also in advising patients as to its possible misuse. Universities generally represent a population where the misuse of $\mathrm{MPH}$ should be better understood and prevented.

\section{References}

1. Bogle $\mathrm{KE}$, Smith $\mathrm{BH}$. Illicit methylphenidate use: a review of prevalence, availability, pharmacology, and consequences. Curr Drug Abuse Rev. 2009;2:157-76.

2. McCabe SE, Knight JR, Teter CJ, Wechsler H. Non-medical use of prescription stimulants among US college students: prevalence and correlates from a national survey. Addiction. 2005;100:96106.

3. McCabe SE, Teter $\mathrm{CJ}$, Boyd CJ. Illicit use of prescription pain medication among college students. Drug Alcohol Depend. 2005;77:37-47.

4. McNiel AD, Muzzin KB, DeWald JP, McCann AL, Schneiderman ED, Scofield J, et al. The nonmedical use of prescription stimulants among dental and dental hygiene students. J Dent Educ. 2011;75:365-76.

5. Mohamed AD, Sahakian BJ. The ethics of elective psychopharmacology. Int J Neuropsychopharmacol. 2012;15:55971. Epub 2011 Mar 14.

6. Hall KM, Irwin MM, Bowman KA, Frankenberger W, Jewett DC. Illicit use of prescribed stimulant medication among college students. J Am Coll Health. 2005;53:167-74.

7. Teter CJ, McCabe SE, Boyd CJ, Guthrie SK. Illicit methylphenidate use in an undergraduate student sample: prevalence and risk factors. Pharmacotherapy. 2003;23:609-17.

8. Barrett SP, Darredeau C, Bordy LE, Pihl RO. Characteristics of methylphenidate misuse in a university student sample. Can J Psychiatry. 2005;50:457-61.

9. McCabe SE1, Teter CJ. Drug use related problems among nonmedical users of prescription stimulants: a web-based survey of college students from a Midwestern university. Drug Alcohol Depend. 2007;91:69-76. Epub 2007 Jul 12.

10. Herman L, Shtayermman O, Aksnes B, Anzalone M, Cormerais A, Liodice $C$. The use of prescription stimulants to enhance academic performance among college students in health care programs. J Physician Assist Educ. 2011;22:15-22.

11. McCabe SE, Cranford JA, Morales M, Young A. Simultaneous and concurrent polydrug use of alcohol and prescription drugs: prevalence, correlates, and consequences. J Stud Alcohol. 2006;67:529-37.

12. Maher B. Poll results: look who's doping. Nature. 2008;452:674-5.

13. Linssen AM, Vuurman EF, Sambeth A, Riedel WJ. Methylphenidate produces selective enhancement of declarative memory consolidation in healthy volunteers. Psychopharmacology (Berl). 2012;221:611-9. Epub $2011 \mathrm{Dec} 15$.

14. Sahakian B, Morein-Zamir S. Professor's little helper. Nature. 2007;450:1157-9.

15. Bostrom N, Sandberg A. Sandberg, Cognitive enhancement: methods, ethics, regulatory challenges. Sci Eng Ethics. 2009;15:311-41. Epub 2009 Jun 19.
16. Outram SM. The use of methylphenidate among students: the future of enhancement? J Med Ethics. 2010;36:198-202.

17. Smith ME, Farah MJ. Are prescription stimulants "smart pills"? The epidemiology and cognitive neuroscience of prescription stimulant use by normal healthy individuals. Psychol Bull. 2011;137:717-41.

18. Kollins SH, MacDonald EK, Rush CR. Assessing the abuse potential of methylphenidate in nonhuman and human subjects: a review. Pharmacol Biochem Behav. 2001;68:611-27.

19. Wilens TE, Adler LA, Adams J, Sgambati S, Rotrosen J, Sawtelle $R$, et al. Misuse and diversion of stimulants prescribed for ADHD: a systematic review of the literature. J Am Acad Child Adolesc Psychiatry. 2008;47:21-31.

20. Volkow ND, Ding YS, Fowler JS, Wang GJ, Logan J, Gatley JS, et al. Is methylphenidate like cocaine? Studies on their pharmacokinetics and distribution in the human brain. Arch Gen Psychiatry. 1995;52:456-63.

21. Volkow ND, Wang GJ, Tomasi D, Kollins SH, Wigal TL, Newcorn $\mathrm{JH}$, et al. Methylphenidate-elicited dopamine increases in ventral striatum are associated with long-term symptom improvement in adults with attention deficit hyperactivity disorder. J Neurosci. 2012;32:841-9.

22. Compton WM, Volkow ND. Abuse of prescription drugs and the risk of addiction. Drug Alcohol Depend. 2006;83:S4-7. Epub 2006 Mar 23.

23. Barrett SP, Pihl RO. Oral methylphenidate-alcohol co-abuse. J Clin Psychopharmacol, 2002;22:633-4.

24. Herman-Stahl MA, Krebs CP, Kroutil LA, Heller DC. Risk and protective factors for methamphetamine use and nonmedical use of prescription stimulants among young adults aged 18 to 25 . Addict Behav. 2007;32:1003-15. Epub 2006 Aug 22

25. Ortega F, Barros D, Caliman L, Itaborahy C, Junqueira L, Ferreira CP. A ritalina no Brasil: produções, discursos e práticas. Interface - Comunic Saude Educ. 2010;14:499-512.

26. Reinert DF, Allen JP. The Alcohol Use Disorders Identification Test (AUDIT): a review of recent research. Alcohol Clin Exp Res. 2002:26:272-9.

27. Saunders JB, Aasland OG, Amundsen A, Grant M. Alcohol consumption and related problems among primary health care patients: WHO collaborative project on early detection of persons with harmful alcohol consumption--I. Addiction. 1993;88:34962.

28. Saunders JB, Aasland OG, Babor TF, de la Fuente JR, Grant M. Development of the Alcohol Use Disorders Identification Test (AUDIT): WHO Collaborative Project on Early Detection of Persons with Harmful Alcohol Consumption--II. Addiction. 1993;88:791804.

29. Fleming MF, Barry $K L$, MacDonald R. The alcohol use disorders identification test (AUDIT) in a college sample. Int J Addict. 1991;26:1173-85

30. Lima CT, Freire AC, Silva AP, Teixeira RM, Farrell M, Prince $M$. Concurrent and construct validity of the audit in an urban brazilian sample. Alcohol Alcohol. 2005;40:584-9. Epub 2005 Sep 5.

31. Mendoza-Sassi RA, Béria JU. Prevalence of alcohol use disorders and associated factors: a population-based study using AUDIT in southern Brazil. Addiction. 2003;98:799-804.

32. Babcock Q, Byrne T. Student perceptions of methylphenidate abuse at a public liberal arts college. J Am Coll Health. 2000;49:143-5

33. Low KG, Gendaszek AE. Illicit use of psychostimulants among college students: a preliminary study. Psychol Health Med. 2002; 7:283-87.

34. Teter CJ1, McCabe SE, Cranford JA, Boyd CJ, Guthrie SK. Prevalence and motives for illicit use of prescription stimulants in an undergraduate student sample. J Am Coll Health. 2005;53:253-62.

\section{Correspondence:}

Betina Lejderman

Rua Engenheiro Olavo Nunes, 99/504, Bela Vista

90440-170 - Porto Alegre, RS - Brazil

Email: betinalejderman@gmail.com 